Available online at : http://ojs.rajawali.ac.id/index.php/JKR

Jurnal Kesehatan Rajawali

ISSN (Print) 2085-7764 | ISSN (Online) 2776-558X |

\title{
Literature Review: Pengaruh Pemberian Aromaterapi Sebagai Intervensi Asuhan Keperawatan Terhadap Tingkat Kecemasan Pada Lansia
}

\author{
Siska Mariani ${ }^{1}$,Eriyono Budi Wijoyo ${ }^{2 *}$, Karina Megasari Winahyu ${ }^{3}$ \\ ${ }^{l}$ Mahasiswa Profesi Ners, Universitas Muhammadiyah Tangerang, Tangerang, Indonesia \\ ${ }^{2}$ Dosen Prodi Profesi Ners, Universitas Muhammadiyah Tangerang, Tangerang, Indonesia \\ ${ }^{3}$ Dosen Prodi Sarjana Keperawatan,Universitas Muhammadiyah Tangerang, Tangerang, Indonesia
}

\begin{tabular}{l}
\hline ARTICLE INFORMATION \\
\hline Received: Desember, 27, 2021 \\
Accepted : February, 08, 2022 \\
Available online: February, 08, 2022
\end{tabular}

\section{KEYWORDS}

Aromaterapi, Tingkat Kecemasan, Lansia,

Literature review

\section{CORRESPONDENCE}

E-mail: eriyonobudi@gmail.com

\section{A B S T T R A C T}

Pendahuluan : Proses menua adalah suatu proses yang ditandai dengan penurunan atau perubahan dari berbagai kondisi fisik, psikologis maupun sosial dalam berinteraksi dengan orang lain. Dari berbagai lansia yang mengalami perubahan fisik akan mempengaruhi kesehatan dan akan menyebabkan penurunan kesejahteraan sehingga dapat menimbulkan masalah psikologi salah satunya adalah kecemasan. Lansia yang mengalami masalah psikologis seperti kecemasan, maka kondisi tersebut dapat mengganggu dalam kegiatan sehari-hari lansia. Salah satu terapi non farmakologi untuk menurunkan tingkat kecemasan yang mudah untuk dilakukan dan terjangkau adalah Aromaterapi. Tujuan : Mengetahui pemberian aromaterapi yang efektif pada penurunan tingkat kecemasan pada lansia berdasarkan Literature Review. Metode : Pencarian artikel menggunakan PubMed, Google Scholar dan World Wide Science, kemudian ditemukan 8 artikel sesuai kriteria inklusi dan eksklusi yang selanjutnya dilakukan review. Hasil : Berdasarkan delapan jurnal yang telah di review bahwa terapi yang efektif untuk menurunkan tingkat kecemasan pada lansia yaitu dengan pemberian aromaterapi dengan essensial oil buah dan bunga. Diskusi : pemberian aromaterapi dapat dilakukan 3-7 hari dan ada beberapa jurnal dilakukan selama 30 hari secara berturut-turut dan pemberian selama 10-15 menit. Kesimpulan : pemberian aromaterapi sangat efektif untuk menurunkan tingkat kecemasan pada lansia karena terapi yang mudah, aman, efektif, non-invasif, dan dapat dilakukan oleh segala usia.

\section{PENDAHULUAN}

Proses menua (aging process) adalah suatu proses yang ditandai dengan penurunan atau perubahan dari berbagai kondisi fisik, psikologis maupun sosial dalam berinteraksi dengan orang lain, proses ini dapat menurunkan fungsi kognitif serta kepikunan, masalah kesehatan kronis dan penurunan fungsi kognitif serta memori (1).

Pada tahun 2020, diperkirakan terdapat 727 juta orang berusia 65 tahun atau lebih di seluruh dunia. Jumlah ini diperkirakan lebih banyak dari dua kali lipat pada tahun 2050, mencapai lebih dari 1,5 miliar orang. Orang tua dalam populasi dunia diperkirakan akan meningkat dari $9,3 \%$ pada tahun 2020 menjadi $16 \%$ pada tahun 2050. Pada pertengahan abad, satu dari enam orang di dunia akan berusia 65 tahun atau lebih tua (2). (World Population Ageing, 2020).

Berdasarkan data proyeksi penduduk, diprediksi jumlah penduduk lansia tahun 2025 sebanyak 33,69 juta jiwa, di tahun 2030 sebanyak 40,95 juta jiwa dan di tahun 2035 menjadi 48,19 juta jiwa. Jumlah penduduk diperkirakan akan terus bertambah menjadi sekitar 450.000 jiwa pertahun (3).

Pada tahap ini, proses penuaan (aging) yang ditandai dengan adanya beberapa perubahan serta penurunan. Perubahan serta penurunan yang dialami lansia seperti psikologis, fisik, kognitif, emosi dan sosial (4). Dari berbagai lansia yang mengalami perubahan fisik akan mempengaruhi kesehatan dan akan menyebabkan penurunan kesejahteraan sehingga dapat menimbulkan masalah psikologi salah satunya adalah kecemasan.

Tingkat prevalensi kecemasan berdasarkan usia dan jenis kelamin, memuncak pada usia dewasa tua (diatas $7,5 \%$ diantara perempuan berusia 55-74 tahun, diatas 5,5\% di antara laki-laki, total perkirasaan jumlah orang yang hidup dengan kondisi kecemasan di dunia ini adalah 264 juta (5). (World Health Organization, 2017). 
Prevalensi terkait kecemasan di Indonesia menunjukkan sekitar $6,1 \%$ yang berusia 15 tahun ke atas atau sekitar 14 juta penduduk. Prevalensi pada usia 55-64 tahun sebanyak 6,9\%, usia 65-74 tahun sebanyak 9,7\% dan usia lebih dari 75 tahun sebanyak 13,4\% (6). Prevalensi menunjukkan bahwa kecemasan terbanyak adalah pada usia lebih dari 75 tahun dan 65-74 tahun atau Lanjut usia. Lansia yang mengalami masalah psikologis seperti kecemasan, maka kondisi tersebut dapat mengganggu dalam kegiatan sehari-hari lansia.

Penatalaksanaan kecemasan ada dua cara yaitu secara farmakologis dan non farmakologis. Obat farmakologis dapat mengobati gangguan psikologis seperti stress, kecemasan dan depresi, tetapi tetap ada efek samping terhadap penggunaan obat tersebut (7). Menurut Kozier, secara non farmakologi terdapat beberapa cara untuk menurunkan tingkat stres seperti yoga, relaksasi nafas dalam, terapi tertawa dan aromaterapi (8). Salah satu terapi non farmakologi untuk menurunkan tingkat kecemasan yang mudah untuk dilakukan dan terjangkau adalah Aromaterapi.

Aromaterapi merupakan salah satu bagian dari pengobatan komplementer yang menggunakan bahan cairan tanaman yang mudah menguap dan dikenal sebagai minyak essensial dan senyawa aromatik lainnya yang dapat mempengaruhi jiwa, emosi dan kesehatan seseorang (9).

Beberapa essensial oil yang sering digunakan dalam aromaterapi karena sifatnya yang serbaguna ialah bunga, buah ataupun herbal. Hal ini didukung oleh penelitian sebelumnya yang melakukan pemberian aromaterapi lavender yang diberikan kepada masingmasing lansia dan didapatkan hasil p-value 0,000 ( $\mathrm{p}<0,05)$, sehingga dapat disimpulkan bahwa ada pengaruh pemberian aromaterapi chamomile terhadap tingkat kecemasan lansia (9).

Berdasarkan latar belakang tersebut masalah yang telah dikemukakan diatas dapat disimpulkan bahwa salah satu masalah yang sering terjadi pada lansia yaitu mengalami kecemasan, stress ataupun depresi. Pada lansia untuk menurunkan tingkat kecemasan dapat diberikan intervensi salah satunya yaitu pemberian aromaterapi. Aromaterapi yang diberikan adalah aromaterapi yang memiliki aroma yang nyaman untuk dihirup dan tidak membuat lansia mengalami efek yang tidak diharapkan. Oleh karena itu peneliti tertarik untuk melakukan studi empiris terkait pemberian aromaterapi tentang judul "Literature Review: Pengaruh Pemberian Aromaterapi Sebagai Intervensi Asuhan Keperawatan Terhadap Tingkat Kecemasan Pada Lansia".

\section{METODE}

Strategi yang digunakan untuk mencari artikel menggunakan PICOT Framework, antara lain sebagai berikut: Population/problem dalam Literature Review ini adalah lansia yang memiliki kecemasan; Intervention dalam Literature Review ini yaitu pemberian aromaterapi; Comparation dalam Literature Review ini menggunakan kelompok intervensi dan kelompok kontrol; Outcome dalam Literature Review ini adalah terdapat pengaruh pemberian aromaterapi terhadap tingkat kecemasan pada lansia; Time dalam Literature Review yang diambil dengan jangka waktu 5 tahun terakhir, yaitu 2016-2021.

Pada pencarian artikel menggunakan keyword dan atau boolean operator (AND, OR, NOT) yang digunakan untuk menspesifikkan atau memperluas pencarian. Sehingga mempermudah dalam pencarian jurnal atapun artikel $(10,11)$. Kata kunci yang digunakan sebagai berikut : "Aromaterapi" atau "Aromatherapy", "Tingkat Kecemasan" atau "Anxiety", "Lansia" atau "Elderly" atau "Older". Database dan laman yang digunakan adalah PubMed (https://pubmed.ncbi.nlm.nih.gov/), Google Scholar (https://scholar.google.com/) dan World Wide Science (https://worldwidescience.org/).

\section{HASIL}

Berdasarkan hasil pencarian literature melalui publikasi di tiga database yaitu Google Scholar, Pubmed dan World Wide Science. Assesment yang dilakukan berdasarkan kelayakan terhadap kriteria inklusi dan eksklusi didapatkan sebanyak 8 artikel yang bisa digunakan dalam literature review. Hasil seleksi studi dapat di gambarkan dalam diagram flow di bawah ini :

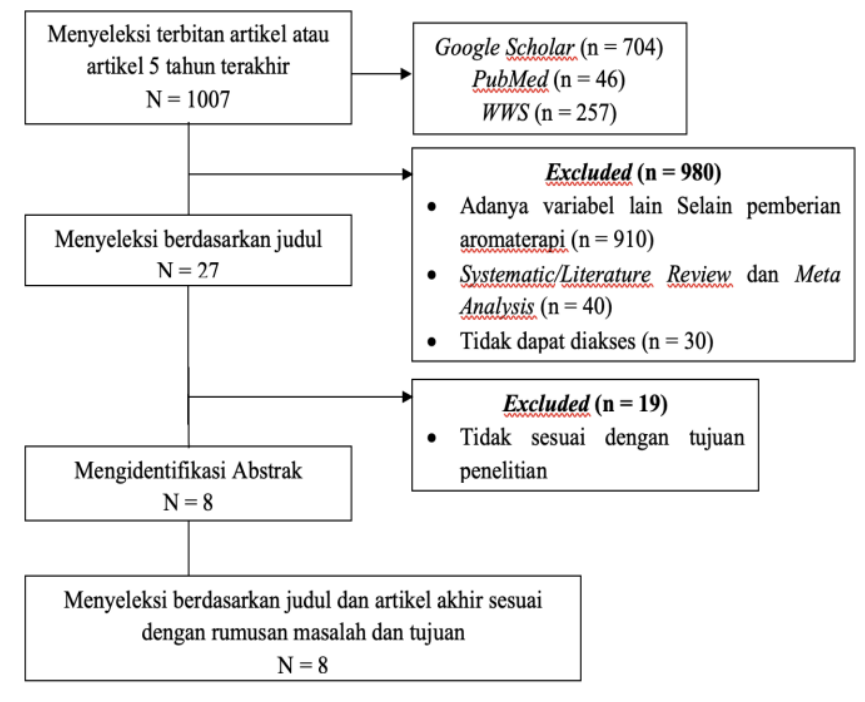

Gambar 1. Diagram Flow

Pada penelitian ini menggunakan delapan artikel yang memenuhi kriteria inklusi, artikel yang dianalisis beragam, metode penelitian tersebut adalah enam jurnal menggunakan Quasy Experimental, satu jurnal menggunakan Pra Experimental dan satu jurnal menggunakan Random Controlled Trial (RCT). Setiap peneliti membahas tentang pengaruh terapi pemberian aromaterapi terhadap penurunan kecemasan atau stress pada lansia. Penelitian ini banyak dilakukan di beberapa wilayah di Indonesia dengan tujuh literature review dan satu jurnal literature review dilakukan di wilayah Iran.

\section{DISKUSI}

Berdasarkan delapan artikel yang telah di review terdapat dua dari delapan artikel menggunakan dua jenis aromaterapi (Chamomile dan Lavender, Rose Damask dan Orange Blossom), dua artikel menggunakan aromaterapi mawar, satu artikel menggunakan aromaterapi chamomile, satu artikel menggunakan aromaterapi lemon, satu artikel menggunakan aromaterapi lavender, dan satu artikel terakhir menggunakan aromaterapi minyak sereh wangi (1, $7,12,13,14,15,16,17)$.

Pemberian aromaterapi terdapat enam dari delapan artikel yang di review menggunakan essensial oil yang ditambahkan air, dan dua artikel dilakukan meneteskan essensial oil ke bola kapas $(7,12$, $13,15,16,17)$. Selanjutnya, durasi dari delapan jurnal yang telah di review terdapat lima artikel yang dilakukan selama 7 hari, satu artikel dilakukan selama 3 hari, satu artikel dilakukan selama 5 hari dam satu artikel dilakukan selama 30 hari $(1,7,12,13,14$, $15,16,17)$. Selanjutnya, terdapat tiga artikel menggunakan skala pengukuran Depresi Anxiety Stress-Scale 42 (DASS), terdapat satu artikel menggunakan skala pengukuran Hamilton Rating 
Scale for Anxiety (HRS-A), terdapat dua artikel menggunakan skala pengukuran Geriatric Anxiety Scale (GAS), satu artikel menggunakan skala pengukuran Perceived Stress Scale (PSS), satu artikel menggunakan skala pengukuran Visual Analog Scale for Anxiety (VAS-A) (1, 7, 12, 13, 14, 15, 16, 17). Dan, terdapat dua dari delapan artikel yang membahas tentang variabel stress, dan didapatkan hasil pemberian aromaterapi dengan $p$-value 0,002 dan $0,007(14,17)$.

Dari delapan Jurnal yang telah di review, mekanisme kerja perawatan aromaterapi dalam tubuh manusia melalui sistem penciuman dimana pembuluh-pembuluh kapiler mengantarkan ke susunan saraf pusat dan oleh otak akan dikirim berupa pesan ke organ tubuh yang mengalami gangguan atau ketidakseimbangan (12). Menurut penelitian sebelumnya menyatakan bahwa aromaterapi pada praktek keperawatan dapat menggunakan essensial oil dari wangi-wangian tumbuhan yang bermanfaat untuk mengurangi masalah kesehatan serta dapat memperbaiki kualitas hidup (13). Terapi yang menggunakan minyak essensial

Tabel 1. Daftar Artikel Hasil Pencarian

\begin{tabular}{|c|c|c|c|c|c|}
\hline No & Study/author & Judul & $\begin{array}{l}\text { Tahun } \\
\text { Terbit }\end{array}$ & Metode Penelitian & Database \\
\hline 1 & $\begin{array}{lrrr}\text { Selvita } & \text { Berlian } & \text { Desta, } & \text { Ratih } \\
\text { Dwilestari } & \text { Puji } & \text { Utami, } & \text { Gatot } \\
\text { Suparmanto } & & & \end{array}$ & $\begin{array}{ll}\text { Pengaruh } & \text { Pemberian } \\
\text { Aromaterapi } & \text { Chamomile } \\
\text { Terhadap Tingkat } & \text { Kecemasan } \\
\text { Lansia Di Desa } \text { Wonokerso }\end{array}$ & 2020 & $\begin{array}{l}\text { Quasy experiment, pre and post test without } \\
\text { control group, dengan pemberian aromaterapi } \\
\text { Chamomile }\end{array}$ & Scholar \\
\hline 2 & $\begin{array}{l}\text { Mohammad Judha, Endang Nurul } \\
\text { Syafitri }\end{array}$ & $\begin{array}{lr}\text { Efektivitas } & \text { Pemberian } \\
\text { Aromaterapilemon Terhadap } \\
\text { Kecemasan Pada Lansia Di } \\
\text { Unit Pelayanan Lanjut Usia } \\
\text { Budi Dharma, Umbulharjo } \\
\text { Yogyakarta }\end{array}$ & 2020 & $\begin{array}{l}\text { Quasy experiment, one group pre post test, } \\
\text { dengan pemberian aromaterapi lemon }\end{array}$ & Scholar \\
\hline 3 & $\begin{array}{lcc}\text { Ika } & \text { Subekti } & \text { Wulandari, } \\
\text { Wahyuningsih Safitri } & \end{array}$ & $\begin{array}{lr}\text { Efektifitas } & \text { Relaksasi } \\
\text { Aromaterapi } & \text { Lavender } \\
\text { Terhadap } & \text { penurunan } \\
\text { Kecemasan di Posyandu Lansi } \\
\text { Desa Plesungan Karanganyar }\end{array}$ & 2016 & $\begin{array}{l}\text { Pre Experiment, One-Group Pretest Postest, } \\
\text { dengan pemberian aromaterapi lavender }\end{array}$ & Scholar \\
\hline 4 & $\begin{array}{l}\text { Hossein Ebrahimia, Abbas Mardanib, } \\
\text { Mohammad Hasan Basirinezhadc, } \\
\text { Azam Hamidzadehd, Fatemeh } \\
\text { Eskandarie }\end{array}$ & $\begin{array}{l}\text { The effects of Lavender and } \\
\text { Chamomile essential oil } \\
\text { inhalation aromatherapy on } \\
\text { depression, anxiety and stress } \\
\text { in older community dwelling } \\
\text { people : A randomized } \\
\text { controlled trial }\end{array}$ & 2020 & $\begin{array}{l}\text { A triple blind, three armed, randomized, and } \\
\text { controlled trial design, dengan pemberian } \\
\text { aromaterapi lavender dan chamomile }\end{array}$ & Scholar \\
\hline 5 & $\begin{array}{l}\text { Zahra Khalili, Zohreh Taraghi, } \\
\text { Ehteram Sadat Ilali }\end{array}$ & $\begin{array}{l}\text { Comparison of the effect of } \\
\text { aromatherapy with essential of } \\
\text { Damask Rose and Citrus } \\
\text { aurantium on the sleep quality } \\
\text { of the elderly people }\end{array}$ & 2021 & $\begin{array}{l}\text { Quasi experiment, Pre Post Test, Without } \\
\text { Control group, dengan pemberian Rose } \\
\text { Damask and Orange Blossom }\end{array}$ & $\begin{array}{l}\text { World Wide } \\
\text { Science }\end{array}$ \\
\hline 6 & $\begin{array}{l}\text { Farideh Bastani, Parvaneh Samady } \\
\text { Kia dan Hamid Haghani }\end{array}$ & $\begin{array}{l}\text { Effect of Aromatherapy with } \\
\text { Damask Rose (Rosa } \\
\text { damascena Mill.) on Anxiety in } \\
\text { the Elderly: Open-Labeled } \\
\text { Quasi-Experimental Placebo- } \\
\text { Controlled Trial }\end{array}$ & 2020 & $\begin{array}{l}\text { Quasi-experiment, Pre Post Test With Control } \\
\text { group, dengan pemberian Rose Damask }\end{array}$ & $\begin{array}{l}\text { World Wide } \\
\text { Science }\end{array}$ \\
\hline 7 & Muhammad Damar Satria & $\begin{array}{lr}\text { Pengaruh } & \text { Pemberian } \\
\text { Aromaterapi Minyak Sereh } \\
\text { Wangi Terhadap Tingkat } \\
\text { Stress Lansia Di Panti Wredha } \\
\text { Dharma Bhakti } \\
\text { Surakarta. }\end{array}$ & 2020 & $\begin{array}{l}\text { Quasy Experiment, pre test and post test non } \\
\text { equivalent control group, dengan pemberian } \\
\text { minyak sereh wangi }\end{array}$ & Scholar \\
\hline 8 & Arif Ferdiyanto & 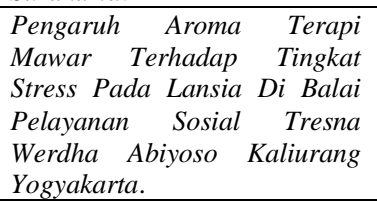 & 2020 & $\begin{array}{l}\text { Quasy eksperiment, non-equivalent control } \\
\text { group, dengan pemberian mawar }\end{array}$ & Scholar \\
\hline
\end{tabular}

bermanfaat untuk mengurangi bahkan dapat mengatasi gangguan psikologis serta gangguan rasa nyaman seperti cemas, depresi, stress, nyeri, dan sebagainya. Dan dari delapan jurnal yang telah di review bahwa terapi yang efektif untuk menurunkan tingkat kecemasan pada lansia yaitu dengan pemberian aromaterapi berbahan dasar buah, bunga dan tumbuhan.

Berdasarkan analisa peneliti, sebagian masyarakat terutama pada lanjut usia lebih tertarik menggunakan terapi non farmakologi atau terapi komplementer dalam menyembuhkan penyakit atau masalah yang dialami pada lansia tersebut. Tindakan non farmakologi atau terapi komplementer dipilih karena terapi yang mudah, aman, efektif, non-invasif, dan dapat dilakukan oleh segala usia. Dari delapan artikel yang telah di review terkait berbagai jenis, cara, durasi dan frekuensi pada pemberian aromaterapi terhadap tingkat kecemasan memberikan pengaruh dan tidak menimbulkan efek yang tidak diharapkan. 


\section{Jurnal Kesehatan Rajawali}

｜ＩSSN (Print) 2085-7764 | ISSN (Online) 2776-558X |

\section{KESIMPULAN}

Berdasarkan delapan jurnal yang sudah di review ini menunjukkan bahwa pemberian aromaterapi dapat dilakukan untuk tingkat kecemasan pada lansia yang diberikan dengan cara seperti essensial oil dicampur dengan air atau diteteskan ke bola kapas dan ditempelkan ke bantal dihirup semalaman. Selanjutnya, essesnsial oil yang dapat digunakan dapat beraroma buah, bunga atau herbal. Dan pemberian aromaterapi dalam artikel yang telah di review rerata diberika selama 10-15 menit dalam 5-7 hari. Hal ini bisa dibuktikan setelah dilakukan intervensi menunjukkan bahwa hasil rerata $p$-value $<0,05$. Kemudian berdasarkan jurnal yang telah di review pemberian aromaterapi dapat dilakukan 3-7 hari dan ada beberapa jurnal dilakukan selama 30 hari secara berturut-turut dan pemberian selama 10-15 menit.

\section{REFERENCES}

1. Desta, Selvita Berlian, Ratih Dwilestari Puji Utami, Gatot Suparmanto. 2020. Pengaruh Pemberian Aromaterapi Chamomile Terhadap Tingkat Kecemasan Lansia Di Desa Wonokerso. Jurnal Keperawatan. Program Studi Keperawatan Program Sarjana Universitas Kusuma Husada Surakarta.

2. World Population Ageing. 2020

3. Kemenkes. 2017. Gambaran Kesehatan Lanjut Usia di Indonesia. Jakarta: Kementrian Kesehatan Republik Indonesia.

4. Azizah \& Rahayu. (2016). Hubungan Self-Esteem dengan Tingkat Kecenderungan Kesepian pada Lansia. Jurnal Penelitian Psikologi, Vol. 7, No. 2, hal. 40-58.

5. World Health Organization. 2017

6. Riskesdas, (2018). Riset Kesehatan Dasar Tahun 2018. Kemenkes RI.

7. Satria, Muhammad Damar. 2020. Pengaruh Pemberian Aromaterapi Minyak Sereh Wangi Terhadap Tingkat Stress Lansia Di Panti Wredha Dharma Bhakti Kasih Surakarta. Naskah Publikasi. Program Studi Keperawatan Program Sarjana Fakultas Ilmu Kesehatan Universitas Kusuma Husada Surakarta.

8. Kozier, et al. (2010). Fundamental Keperawatan. Jakarta: ECG.

9. Hidayati, Ramadhania Bella Nur, Ari Widyaningsih, Moneca Diah Lestari. 2019.Pengaruh Aromaterapi Lavenderterhadap Penurunan Nyeri Dismenore Pada Mahasiswa Kebidanan Universitas Ngudi Waluyo. Universitas Ngudi Waluyo: Skripsi.

11. Nursalam, P and Hons, M. N. 2020. Pedoman Penyusunan Skripsi-Literature Review dan TesisSystematic Review Alih Pembelajaran Akibat Pandemi (April). p.31

12. Perdani, Zulia Putri; Hastuti, Hera; Kartini; Yoyoh, Imas. 2020. Panduan Literature Review : Program Studi
Pendidikan Profesi Ners. Fakultas Ilmu Kesehatan Universitas Muhammadiyah Tangerang.

13. Judha, Mohhamad., Syafitri, Endang Nurul. 2018. Efektivitas Pemberian Aromaterapilemon Terhadap Kecemasan Pada Lansia Di Unit Pelayanan Lanjut Usia Budi Dharma, Umbulharjo Yogyakarta. Jurnal Keperawatan Respati Yogyakarta. Program Studi S1 Ilmu keperawatan \& Pendidikan Profesi Ners, Fakultas Ilmu Kesehatan, Universitas Respati Yogyakarta. pISSN: 2088-8872; e-ISSN: 2541-2728.

14. Ferdiyanto, Arif. 2017. Pengaruh Aroma Terapi Mawar Terhadap Tingkat Stress Pada Lansia Di Balai Pelayanan Sosial Tresna Werdha Abiyoso Kaliurang Yogyakarta. Naskah Publikasi. Program Studi S-1 Ilmu Keperawatan Fakultas Ilmu-Ilmu Kesehatan Universitas Alma Ata Yogyakarta

15. Ebrahimi, Hossein, Abbas Mardanib, Mohammad Hasan Basirinezhadc, Azam Hamidzadehd, Fatemeh Eskandarie. 2020. The effects of Lavender and Chamomile essential oil inhalation aromatherapy on depression, anxiety and stress in older community dwelling people : A randomized controlled trial. Elsevier Inc. https://doi.org/10.1016/j.explore.2020.12.012 15508307

16. Wulandari, Ika Subekti., Safitri, Wahyuningsih. 2016. Efektifitas Relaksasi Aromaterapi Lavender Terhadap penurunan Kecemasan di Posyandu Lansi Desa Plesungan Karanganyar. Jurnal KesMaDaSka. Program S-1 Keperawatan STIKes Kusuma Husada Surakarta.

17. Khalili, Zahr, Zohreh Taraghi, Ehteram Sadat Ilali. 2021. Comparison of the effect of aromatherapy with essential of Damask Rose and Citrus aurantium on the sleep quality of the elderly people. Journal of Nursing and Midwifery Sciences. Vol.8: 1.Page: 9-14.

18. Bastani F, Samady Kia P, Haghani H. Effect of Aromatherapy with Damask Rose (Rosa damascena Mill.) on Anxiety in the Elderly: OpenLabeled Quasi-Experimental Placebo-Controlled Trial, Iran J Psychiatry Behav Sci. 2020 ; 14(4):e58064. doi: 10.5812/ijpbs.58064. 